\title{
IDOSOS E CHIKUNGUNYA: CONTRIBUIÇÕES PARA UM ESTUDO DE CASO EM UMA COZINHA DOMÉSTICA
}

\author{
SENA, Renan (1); \\ BARROS, Bruno (2) \\ (1) UFCG, Bacharel \\ e-mail: renan sena castro@hotmail.com \\ (2) UFPE, Mestre \\ e-mail: barros bruno@hotmail.com
}

\begin{abstract}
RESUMO
Uma nova preocupação para a saúde de indivíduos idosos tem sido a Chikungunya, uma vez que a enfermidade desencadeia e/ou potencializa problemas permanentes, como a Artrite Reumatoide. Dentro deste contexto, a corrente investigação objetivou a análise das necessidades e limitações do usuário idoso acometido pela Chikungunya e suas consequências permanentes em um estudo de caso. Para tanto, lançamos mão da Metodologia para Projetos de Construção Centrados no Ser Humano. Os resultados alcançaram recomendações e um projeto conceitual que considera as limitações deste tipo de usuários, bem como a proposição de parâmetros para novos projetos do gênero.
\end{abstract}

Palavras chave: Idosos, Ambientes Domésticos, Chikungunya.

\section{ABSTRACT (11 PTS, NEGRITO)}

A new concern for elderly health has been the Chikungunya as it triggers and / or potentiates permanent problems such as Rheumatoid Arthritis. Due to the higher proactive performance of the elderly population, it is important to think about optimizing the autonomy of this user in residential environments. Within this context, current research aimed at analyzing the needs and limitations of the elderly user affected by Chikungunya and its permanent consequences in a case study to develop the conceptual design of a residential kitchen environment. To do so, we use the Methodology for Human- Centered Construction Projects. The results reached guidelines and a conceptual design that considers the limitations of this type of long-lived users, as well as the proposition of parameters for new projects of the genre.

Keywords: Elderly, Domestic Environments, Chikungunya.

\section{INTRODUÇÃO}

Somadas às limitações naturais decorrentes do envelhecimento, ainda surgem os riscos de contração de doenças, as quais podem vir a agregar ou desencadear ainda mais sintomas limitantes. Uma das doenças que têm preocupado a sociedade nos últimos anos é a Chikungunya, notadamente no público longevo (mais frágil aos sintomas). Segundo a OMS (Organização Mundial da Saúde, 2005), a Chikungunya é uma doença infecciosa febril, causada pelo vírus Chikungunya ( $\mathrm{CHIKV})$, podendo ser transmitida pelos mosquitos Aedes 


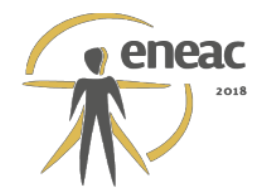

aegypti e Aedes albopictus. O termo que dá nome a doença significa "aqueles que se dobram", referindo-se à aparência curvada dos pacientes que foram atendidos no início da epidemia no mundo (no continente africano). Os sintomas são febre alta, e dores intensas nas articulações. A Chikungunya tem como característica a capacidade de desencadear ou potencializar problemas articulares, como a Artrite Reumatóide. Desta forma, torna-se necessária a promoção de pesquisas, paralelas ao avanço médico científico, as quais considerem as limitações permanentes geradas pelas consequências desta doença na concepção de ambientes domésticos.

Tendo como foco a análise, geração de recomendações e concepção de espaços ergonomicamente adequados, a Ergonomia do Ambiente Construído se configura importante aliada na composição de ambientes domésticos salutares. Nesse contexto, este artigo tem como principal objetivo considerar as consequências permanentes da Chikungunya, somadas às limitações decorrentes do processo de envelhecimento, para, a partir de então, expor a análise de um estudo de caso do ambiente da cozinha residencial de um estudo de caso. Como guia procedimental investigativo e projetual, lançamos mão da Metodologia para Projetos de Construção Centrados no Usuário, encontrada em Attaianese e Duca (2012). Esta metodologia é composta por sete etapas, onde cada uma tem sua condução metodológica peculiar consoante com a condução do estudo. Essa metodologia consiste principalmente em projetar a construção dos ambientes de forma centrada no ser humano.

Acreditamos que o público idoso requer necessidades específicas no ambiente e, em casos de indivíduos que sofrem com as consequências da Chikungunya, essas necessidades são ainda mais contundentes. Desta forma, uma cozinha planejada para uma família de jovens adultos pode oferecer sérios riscos à utilização por parte de um longevo. As inadequações podem implicar em dores, inflamações, quedas, cortes e contusões, como também a não utilização de parte do mobiliário devido a um alcance inacessível.

\section{FUNDAMENTAÇÃO TEÓRICA}

\subsection{Limitações e sinais do envelhecimento}

Com o avanço da idade, o ser humano apresenta sinais e perda de capacidades regenerativas, além de limitações que surgem progressivamente, esse é o processo de envelhecimento fisiológico, o qual pode vir a trazer alguns impactos no corpo. Alguns destes impactos podem se expressarem em forma rugas; manchas na pele; comprometimento visual e auditivo; perdas de memória; perda de massa e redução do tônus muscular; perda de cálcio nos ossos; perda de memória; rigidez articular e redução da amplitude de movimento, além de alterações na marcha e no equilíbrio, as quais podem acarretar em uma predisposição a quedas, dores e incapacidade funcional (CLARES, FREITAS, BORGES, 2013; OMS, 2008).

No âmbito da saúde pública, o declínio da função visual dos idosos é fonte de preocupação. A maioria dos idosos não se queixa da visão, mesmo que ela já esteja se degradando, por considerarem como uma causa da idade avançada. O comprometimento visual geralmente se define pela acuidade visual, que é parte da visão funcional de um indivíduo. A acuidade visual é o parâmetro que expressa de forma mais genérica a capacidade de discriminação de formas e contrastes, ou seja, a capacidade de ver os detalhes, além de ser um método para se medir o reconhecimento da distância entre dois pontos no espaço e da resolução de suas respectivas imagens sobre a retina. A OMS utiliza a acuidade visual como critério para definir 0 comprometimento visual, pois é o melhor valor que, sozinho, caracteriza a perda visual (LUIZ, REBELATTO, COIMBRA, RICCI, 2009). É visto também, que a perda dessa acuidade caracteriza-se pela perda de transparência no cristalino, e o humor vítreo, fazendo 


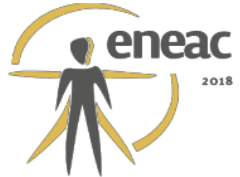

com que os idosos precisem de uma iluminação mais intensa (IIDA, 2005). Dentro deste contexto, encontramos em Molina, Braida e Abdalla (2015) o recurso de utilização da diferenciação cromática para facilitar a visualização dos elementos no ambiente através do contraste de cor.

Outro fator a ser observado é relacionado ao declínio da capacidade de manejo (ação de movimentar, adquirir ou acessar o funcionamento de um produto, pelo qual é possível enviar movimentos de comando e controle na realização de atos). IIDA (2005) descreve que a mão humana é um dos instrumentos mais versáteis, completos e sensíveis, e que devido a sua mobilidade, é possível conseguir uma grande variedade de manejos com variações de precisão e força. O manejo pode ser classificado em fino e grosseiro.

Segundo IIDA (2005) o manejo fino também conhecido como de precisão, envolve basicamente a ponta dos dedos, deixando o punho e a palma da mão parados. Os movimentos são precisos e rápidos, porém não exigem muita força, mas é importante observarmos que, pelo fato da gradativa perda dessa habilidade, o idoso começa a perder autonomia com o passar do tempo, o que gera a necessidade de uma busca por soluções para esse tipo de problema na concepção de projetos de produtos e ambientes.

\subsection{A chikungunya: sintomas e sequelas}

De acordo com o Ministério da Saúde (2015), até 70\% das pessoas que são infectadas pelo vírus CHIKV apresentam sintomas. Quando comparados com outras arboviroses, nota-se que esses valores são altos e significativos. Após a picada do vetor, o indivíduo tem o vírus inoculado em seu corpo, que é rapidamente espalhado, causando uma infecção aguda que causa artralgia, poliartralgia, mialgia, dores de cabeça, exantema, conjuntivite, náuseas, manchas avermelhadas na pele e febres repentinas (TORTORA; FUNKE; CASE 2012). Os sintomas da Chikungunya podem ser confundidos facilmente com os da Dengue, mas uma grande diferença entre eles é que o vírus da Chikungunya traz intensas dores nas articulações e nos músculos, dificultando e limitando bastante a realização de seus movimentos (TORTORA; FUNKE; CASE 2012; BRASIL, 2014). Geralmente os sintomas imediatos dessa doença persistiriam por um tempo de 10 a 15 dias, mas registros mostram vários casos onde estes sintomas tornaram-se crônicos, durando meses ou até anos (BRASIL, 2011). Esses fatores revelam uma enfermidade a qual precisa ser fortemente considerada, devido a seus vários transtornos e complicações à saúde humana.

A Chikungunya tem a capacidade de desencadear problemas permanentes em idosos, como a artrite reumatoide. A Artrite Reumatoide (AR) é uma doença autoimune, com sua etiologia desconhecida, e é caracterizada por poli artrite simétrica, que faz com que as articulações sofram deformidades e se destruam, por conta do desgaste dos ossos e da cartilagem (BIASOLI, 2007; LIPSKI, 1998). É uma doença que passa a ser importante nesse estudo por conta de seus sintomas, as sequelas que deixa e as limitações que causa.

Segundo a Sociedade Brasileira de Reumatologia (2011) a Artrite Reumatoide (AR) geralmente inicia-se com apenas uma, ou poucas articulações inchadas, quentes e dolorosas, geralmente ocorre uma dificuldade de movimentação principalmente pela manhã, e podendo durar por horas, por conta da rigidez apresentada por essas articulações.

De acordo com American College of Rheumatology (2002), a AR ataca pequenas e grandes articulações junto com manifestações sistêmicas, como: rigidez matinal, fadiga e perda de peso. Quando o problema envolve outros órgãos, a morbidade e a gravidade da doença aumentam, podendo causar diminuição da expectativa de vida do indivíduo acometido. Com a evolução da enfermidade, os pacientes com AR começam a perder a capacidade para a realização de atividades diárias, e do meio profissional (AMERICAN COLLEGE OF RHEUMATOLOGY, 2002; SOCIEDADE BRASILEIRA DE REUMATOLOGIA, 2011). 


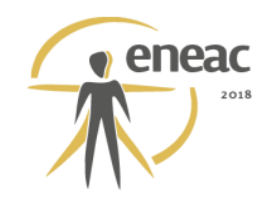

Brasil (2015) reforça que a principal manifestação clínica da Chikungunia é a ocorrência das fortes dores nas articulações, estes sintomas podem durar até três anos subsequentes à contração da enfermidade. Desta forma, considerar a AR como consequente agravante, traz ainda mais parâmetros para o desenvolvimento de projetos residenciais assistivos, tornando possível a adequação de um maior número de elementos.

\subsection{Ergonomia do Ambiente Construído e cozinhas domésticas}

A maioria dos acidentes com idosos acima de 60 anos acontece em suas residências, deste modo torna-se fundamental a intervenção da qualidade de vida dos idosos no que diz respeito a seus domicílios. Assim, é preciso que sejam utilizadas algumas medidas ergonômicas simples, mas que serão de grande ajuda evitando vários acidentes domiciliares (ARAÚJO et al., 2008 p.3). Alguns fatores de risco são influenciados por características do ambiente, tais como, iluminação, superfícies escorregadias, tapetes, degraus, obstáculos e irregularidades no relevo. Também se deve considerar o piso, muitas vezes escorregadio e/ou desnivelado; soleiras em relevo; presença de tapetes, principalmente soltos; iluminação inadequada, ausente ou precária; mobiliário inadequado, com quinas pontiagudas e/ou instalados com altura que exige o uso de escadas ou bancos; layout em desconformidade com o espaço, dificultando a mobilidade ou obstruindo a passagem; maçanetas de difícil manuseio, em sua maioria arredondadas; interruptores mal posicionados, muitas vezes excessivamente baixos ou distantes do ponto de acesso ao ambiente; degraus sem faixa antiderrapante (MOLINA, BRAIDA, ABDALLA; 2015).

O ambiente construído deve apresentar características físicas com caráter prático e utilitário, relacionados aos aspectos mecânicos da função e da atividade desenvolvida no ambiente. $\mathrm{Na}$ abordagem ergonômica, ao visar às atividades dos indivíduos, a diversidade humana passa a ser um parâmetro de projeto em que se consideram as capacidades e limitações variadas dos indivíduos (ATTAIANESE, DUCA, 2012). Neste sentido, torna-se fundamentalmente relevante que o planejamento adequado de ambientes considere soluções de compensação ou minimização das perdas funcionais, provenientes do processo natural de envelhecimento ou de alguma deficiência qualquer, aumentando dessa forma a possibilidade de melhor desempenho do usuário buscando, assim, evitar a sensação de dependência e inatividade, que podem levar a depressão (SÂMIA, 2008).

Dentre os espaços residenciais em que a Ergonomia do Ambiente Construído pode contribuir, podemos citar o ambiente de cozinha como um dos locais mais importantes da casa, bem como um ambiente com maior movimento de atividades. Neufert (2013) expõe que a cozinha é um local de trabalho onde os indivíduos permanecem por várias horas. Este ambiente também pode ser utilizado como ponto de encontro da família, nos momentos de refeição. Neste ponto, ressaltamos a necessidade de um grande cuidado com dimensionamentos nos projetos de cozinhas.

\section{METODOLOGIA}

Como guia de procedimentos investigativos para o desenvolvimento da corrente pesquisa, lançou-se mão da Metodologia para Projetos de Construção Centrados no Usuário, desenvolvida pelas autoras Attaianese e Duca (2012). Esta metodologia consiste, em sua essência, em fornecer caminhos para a concepção do projeto de um ambiente centrado no ser humano. O processo é caracterizado pela formação de sete etapas, porém, neste estudo, apenas as cinco primeiras 5 foram comtempladas. Esta seleção destas etapas devese ao fato de que, para realização das duas últimas fases, é necessário que a edificação esteja construída, o que não ocorreu até o momento de composição deste artigo. Dentre as 


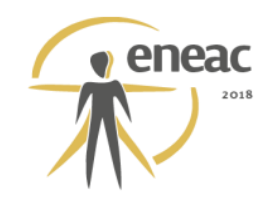

etapas contempladas neste estudo, a etapa de Briefing de Design buscou reunir informações sobre os requisitos necessários ao ambiente para satisfazer as demandas dos usuários. Na segunda etapa, Perfis de Usuários e Grupos de Ajuste, foi feita a caracterização dos usuários e foram identificados os grupos de usuários (diretos, indiretos), suas características pessoais e estado de uso do ambiente.

A Análise da Tarefa, terceira etapa metodológica, destinou-se a descrever as atividades realizadas no ambiente pelo usuário em foco, sendo verificados os requisitos necessários, e posturas assumidas na realização das tarefas, condições e constrangimentos do ambiente. A quarta etapa, Adaptação às Necessidades dos Usuários, consiste na compilação de todos os dados obtidos nas etapas anteriores, gerando, ao final, a lista de recomendações ergonômicas. Na última etapa, Primeiros Detalhes Arquitetônicos, dedicou-se à elaboração de um projeto conceitual de referência para os usuários do espaço.

\subsection{Apresentação do local do estudo de caso}

O estudo de campo foi realizado em um município do interior do estado ao qual faz parte, e é caracterizado por ser a terceira maior cidade do interior em população, com 87.538 habitantes (IBGE, 2010). A residência possui apenas um pavimento, subdividido em sete cômodos, no entanto, há apenas uma moradora, a qual foi acometida Chikungunya e sofre com as sequelas deixadas pela enfermidade (Artrite Reumatóide). O ambiente selecionado para análise foi a cozinha, cuja imagem pode ser acompanhada na figura 1 que se segue.

Figura 1 - Ambiente de cozinha analisado.

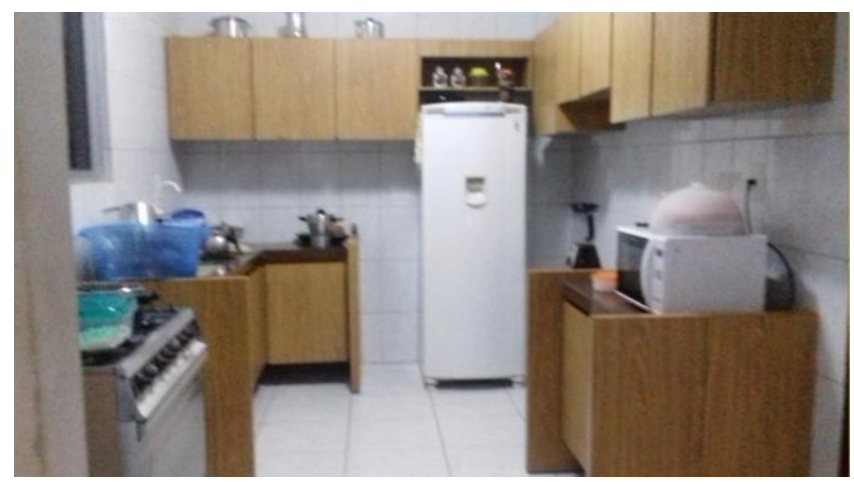

Fonte: Capturado pelo autor para a pesquisa.

A cozinha analisada apresenta uma área total de $10,47 \mathrm{~m}^{2}(2,565 \times 4,085)$, possui um leiaute em "U" e é composta pelo mobiliário planejado sob medida para uma outra edificação (residência anterior da moradora).

\section{RESULTADOS}

\subsection{Briefing}

De imediato, a primeira observação revelou aspectos corretivos e requisitos projetuais essenciais para a concepção do ambiente. A cozinha para o usuário idoso em questão, 


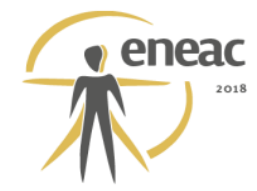

acometido de Chikungunia, demandava elementos como amplitude no espaço e circulação adequada. Desta forma, se fazia necessário pensar em opções para otimização dos espaços. Também ficou evidente que a iluminação artificial do cômodo precisava ser repensada para trazer mais visibilidade ao ambiente de trabalho em momentos do dia em que a iluminação natural não se mostrava suficiente.

Em adição, alguns móveis demandavam um alcance manual mais acessível, além disso, careciam de puxadores adequados, para trazer uma melhoria no ato de abrir e fechar das portas. No mobiliário existente no local, o tamponamento também foi utilizado como reforço para os armários, mas possuía uma profundidade que sacava muito do armário, e poderia atuar como obstáculo e fonte de colisões, contusões e lesões. Desta forma, o mobiliário do ambiente também se revelou como elemento de necessidade emergencial de ajuste.

\subsection{Perfis de Usuários e Grupos de Ajuste}

A usuária direta nesse estudo é uma pessoa de baixa estatura, possuindo 1,53m, e com 60 anos de idade. A usuária foi acometida de Chikungunya a pouco menos de um ano do término desta pesquisa e ainda sofre com algumas sequelas, como as dores, desconforto e restrições de mobilidade causadas pela artrite reumatoide desencadeada. Como usuários indiretos, viu-se que podem ser considerados apenas os indivíduos que utilizam eventualmente o ambiente da cozinha, como familiares em suas raras visitas.

Foi aplicada a técnica de Walkthrough, a qual identificou detalhadamente os elementos compositivos do ambiente. Nesta descrição, podemos destacar o formato da cozinha, o qual é retangular, com aproximadamente $10 \mathrm{~m}^{2}$. O leiaute do ambiente é disposto em "U", com mobiliário inferior com bancada de granito e mobiliário superior de armários, além dos equipamentos eletrodomésticos que compõem o ambiente.

\subsection{Análise da Tarefa}

Para a realização da análise da tarefa, identificaram-se, juntamente com a usuária, as principais atividades realizadas no ambiente, a saber: cozinhar, lavar a louça, limpar cozinha, preparo de refeições, guardar e retirar objetos de uso e suprimentos no mobiliário e geladeira, beber água, posicionar garrafão de água, e circulação. O acompanhamento da idosa utilizando o ambiente revelou que, para lavar louça, a pouca altura do balcão, e sua profundidade elevada, causavam uma postura inadequada, pois gera uma inclinação da coluna lombar, o que pode causar dores nessa região (figura 2 A). Também ficou evidente que as atividades de limpeza e retirada de objetos dos armários oferece riscos. Existe uma desorganização nos lugares dos suprimentos, e na frequência de uso relacionada com a distância dos mesmos. Alguns produtos estão fora do alcance da usuária, obrigando-a a fazer um grande esforço se esticando para alcançar, assumindo uma postura onde eleva bastante os membros superiores e segura os objetos, causando desconfortos nas regiões do ombro, nos membros superiores, e forçando os tornozelos por estar na ponta dos pés (figura 2 B,C e D).

A observação também identificou que as portas dos móveis não possuem puxadores. Nas portas superiores não existem sérios problemas, pois elas dispõem de uma borda que sobra do móvel, a qual pode ser utilizada para puxar e abri-lo. Nas portas inferiores existe o risco de prender a mão ou os dedos entre a porta e a bancada de granito imediatamente superior à sua estrutura (como, de acordo com a usuária, ocorre com frequência) (figura 3). 


\section{(x) $^{\text {enac }}$}

Figura 2 - Inadequações percebidas no ato de lavar louça, fazer limpeza e retirar objetos.

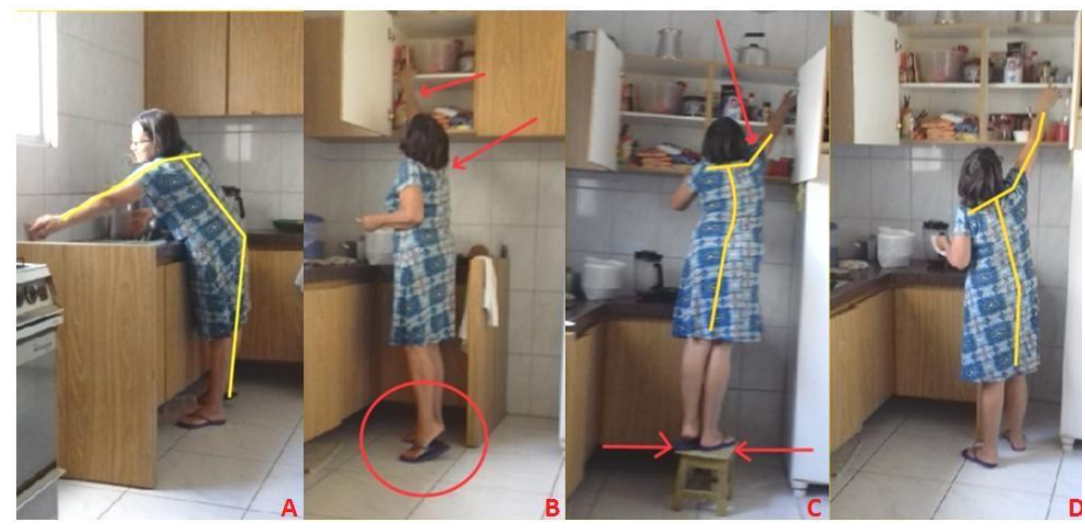

Fonte: Capturado pelos autores para a pesquisa.

Figura 3 - Procedimento de abertura dos móveis.

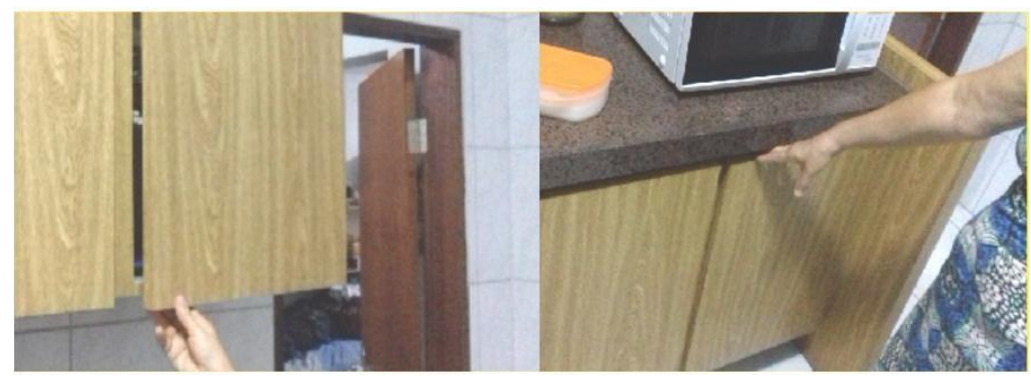

Fonte: Capturado pelos autores para a pesquisa.

A análise da tarefa também identificou inadequações relacionadas ao alcance manual na atividade de abrir a janela e trocar o garrafão de água mineral (sendo esta última somada ao peso do garrafão). Verificou-se ainda que o armário inferior impede a abertura total da porta do refrigerador e o revestimento melamínico dos móveis apresenta vários pontos de descolamento e fratura, expondo uma série de extremidades pontiagudas.

Agregado a estes fatores, viu-se que o ambiente é dotado de um esquema monótono de cores (branco e cáqui), onde a falta de contrastes entre elementos dos móveis dificulta a visualização de detalhes. Este fator cromático nos estimulou a uma verificação do conforto ambiental oferecido pelo ambiente. Munidos de termômetro, iluminômetro e decibelímetro devidamente calibrados, realizou-se aferições em horários distribuídos ao logo do dia. No que diz respeito à temperatura, pela manhã, as $8 \mathrm{~h} 00$, a temperatura registrada foi de $23^{\circ} \mathrm{C}$; as $12 \mathrm{~h} 30$ a temperatura alcançou $30^{\circ} \mathrm{C}$; e as $17 \mathrm{~h} 30$ a temperatura encontrava-se em $25^{\circ} \mathrm{C}$. Apenas em um dos horários aferidos (8h00) a temperatura se mostrou em acordo com a NR17 (entre $20^{\circ}$ e $23^{\circ} \mathrm{C}$ ), no entanto, devemos considerar a maior sensibilidade dos idosos a baixas temperaturas, a qual é reforçada pela artrite reumatoide e pela menor tolerância característica dos indivíduos residentes em cidades de clima quente.

No que tange ao ruído, não foram identificados valores elevados, nem mesmo em decorrência do uso do liquidificador, o qual, de acordo com a usuária, é o eletrodoméstico de maior produção de ruído na residência.

Os parâmetros de iluminação verificados mostraram que, as $8 \mathrm{~h} 00$, o índice esteve entre 75 e $85 \mathrm{Lx}$; mais tarde, às $12 \mathrm{~h} 30$, alcançou entre 95 e $105 \mathrm{Lx}$; e durante o fim da tarde as 17h30, o índice se encontrava entre 70 e 80 Lx. Nota-se que os índices de iluminância encontram-se inadequados, por estar abaixo dos níveis indicados pelas normas da ABNT 


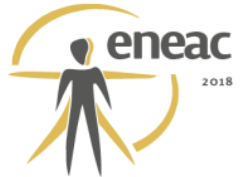

NBR 5413:1992, que são entre 300 e 500 Lx. Ainda devemos destacar a maior necessidade de intensidade de iluminação por parte do público idoso (atentando para se evitar reflexos luminosos).

De modo a suplementar a análise, foi vista a necessidade de realizar uma investigação antropométrica do ambiente, desta forma, tomamos como referência as dimensões sugeridas por Panero e Zelnik (2013) para o ambiente de cozinha doméstica. A verificação identificou as seguintes inadequações: altura insuficiente e profundidade excessiva da bancada de granito; área de circulação insuficiente próximo à entrada e no centro da cozinha; altura insuficiente do armário inferior; profundidade excessiva dos tamponamentos dos móveis; distância excessiva entre o balcão e a base dos armários superiores; e altura e profundidade excessiva dos armários superiores.

\subsection{Adaptação às necessidades dos usuários}

Nesta etapa, foram discutidas as principais necessidades para o espaço e verificadas as possibilidades de adaptações do ambiente, gerando por fim a lista de recomendações ergonômicas dispostas a seguir:

- Distribuir homogeneamente o mobiliário, para melhorar circulação, facilitar atividades, ajudar na organização e na composição formal do ambiente;

- Uniformizar as dimensões do mobiliário, melhorando seu funcionamento e seu aspecto visual;

- Fixar armários superiores antropometricamente mais acessíveis na altura, para permitir o alcance manual superior por parte do idoso;

- Fixar armários inferiores mais distantes do piso, para evitar que a usuária se abaixe excessivamente;

- Dispor de armários inferiores de modo suspenso, para facilitar a limpeza abaixo do móvel;

- Optar por armários superiores com acabamento até o teto (apenas para objetos com mínima frequência de uso), com acesso através de escada pequena, e também para evitar o acúmulo de poeira em cima do mobiliário, causando a necessidade de limpeza constante;

- Dispor de mais espaço nos armários para guardar todos os objetos, para os casos em que não existe dispensa na cozinha;

- Aplicar uma diferenciação cromática entre portas, gavetas e esquadrias, para promover a percepção destes elementos no ambiente. Este recurso torna-se necessário pela gradativa redução da acuidade visual;

- Utilizar cores e texturas que tragam mais energia, vivacidade e aconchego, tornando o ambiente mais estimulante, além de buscar uma eficácia visual e tátil;

- Organizar de objetos e produtos de consumo de acordo com frequência de uso, tamanho e peso, para facilitar a tarefa de guardar e retirar os produtos dos armários;

- Dispor de espaço para guardar escada, a qual servirá para pegar objetos com pouca frequência de uso, guardados em locais mais altos;

- Optar por uma escada leve e desmontável (substituindo banquinhos, que podem tombar facilmente), para auxiliar na busca por objetos em locais menos acessíveis (mínima utilização);

- Fixar tampo de bancada de granito com altura mais elevada e profundidade menor, para evitar flexões acentuadas na coluna lombar e consequente desconforto e até lesões na coluna; 


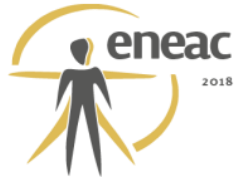

- Especificar tamponamentos não sacados dos armários, com espaço apenas para acomodar as portas de forma rente, para evitar lesões por contusão e facilitar a limpeza e a circulação;

- Especificar gaveteiros adequados para a pega de idosos, os quais precisam utilizar vários dedos da mão para ter força e abrir a porta, por conta da debilidade de manejo fino. Essa adequação trará mais agilidade e segurança ao utilizar gavetas;

- Indicar gavetas do mobiliário inferior do tipo gavetão, para evitar que idosos se abaixem excessivamente;

- Especificar puxadores adequados em mobiliários e janela, para realizar com segurança e conforto a tarefa de abrir e fechar as portas de moveis e janela. As pegas e puxadores devem ser adequados para a capacidade e familiaridade do idoso, de forma a facilitar a tarefa, com sistemas deslizantes e abertura de portas leves, por conta da redução da capacidade de manejo fino, e a perda do tônus muscular;

- Projetar móvel para bebedouro acoplado ao restante do mobiliário, com prateleira de altura regulável, para tornar menos desgastante a tarefa de limpar e colocar o garrafão de água no bebedouro. $O$ bebedouro deve ser localizado na bancada de granito junto com móvel específico, para facilitar as tarefas de limpeza, posição e remoção do garrafão;

- Especificar local para dispor micro-ondas, evitando que seja disposto na bancada de trabalho, onde pode atrapalhar as atividades;

- Instalar coifa ou depurador de ar para evitar fixação de cheiros e o acúmulo de gordura e fumaça no ambiente de cozinha;

- Propor uma iluminação artificial reforçada, mas dentro dos limites da ABNT, para ajudar a iluminação natural a trazer uma boa iluminação para o ambiente;

- Eliminar objetos desnecessários dispostos na circulação do ambiente, para não comprometer a área de fluxo na realização das atividades;

- Reduzir a quantidade de informação visual, para evitar cansaço mental e estresse na usuária;

- Reduzir quantidade de pequenos objetos à mostra no ambiente, devido à redução de acuidade visual, que diminui a percepção de detalhes;

- Evitar equipamentos demasiados apresentando-se como obstáculos, trazendo riscos de lesão por contusão;

- Eliminar a aplicação de tons muito escuros, pois causaria uma diminuição nos índices de iluminação;

- Evitar a especificação de espelhos e materiais de alto brilho em grandes espaços, devido ao risco de causar ofuscamentos por reflexos de luz para a usuária;

- O mobiliário não deve possuir sistemas de abertura por toque, devido à falta de familiaridade de idosos com tal tecnologia, acarretando dúvidas sobre a abertura das portas e gavetas.

\subsection{Primeiros Detalhes Arquitetônicos}

Nesta etapa foi dedicada à concepção de um projeto conceitual, onde se buscou contemplar as demandas ergonômicas identificadas nas análises. Desta forma, o leiaute do espaço permaneceria em "U", permitindo estações de trabalho em três setores do ambiente, formando um triângulo funcional. Outra modificação foi em relação ao mobiliário superior, o qual ficou mais próximo ao piso, com elevação de $137 \mathrm{~cm}$, visando o alcance manual de 


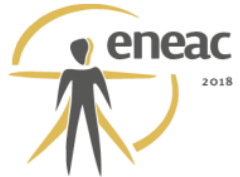

usuários idosos. Os armários superiores ficaram maiores, ganhando em altura, e o projeto dispõe de um sistema mecânico deslizante que traz a possibilidade de puxar toda a estrutura interna das prateleiras para baixo, facilitando o acesso ao conteúdo interno (mecanismo sugerido por BEZERRA e BARROS, 2014).

Figura 4 - Visão geral do projeto conceitual.

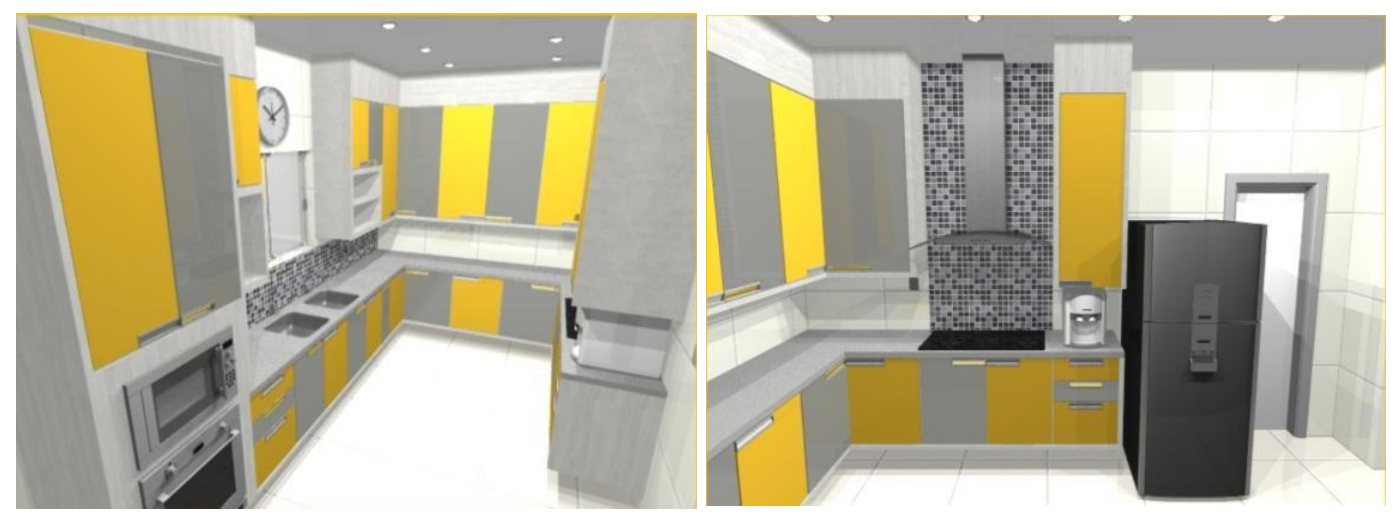

Fonte: Elaborado pelos autores para a pesquisa.

O sistema de iluminação utilizado foi um sistema de lâmpadas de LED, com controle de unidade e de intensidade, para auxiliar a iluminação natural nos momentos necessários, sem que haja um ofuscamento por iluminação demasiada, mas permitindo maiores intensidades. O contraste de cores e texturas foi cuidadosamente escolhido de acordo com as recomendações ergonômicas, considerando principalmente a perda da acuidade visual dos idosos e permitindo a diferenciação clara entre os elementos do ambiente. Os puxadores dispostos em todo o mobiliário são embutidos, e com proteção nas laterais, podem ser acionados com todos os dedos da mão, e não necessitam de manejo fino. Esses puxadores não sacam do móvel, e por isso reduzem o risco de acidentes e lesões por contusão. Um fator importante foi a familiaridade do produto com o usuário, o puxador teve seu tamanho reduzido, sendo instalado apenas no local que deve ser utilizado para abrir a porta, reduzindo o risco de erro. O tamponamento dos armários superiores segue até o teto, impedindo o acúmulo de poeira e eliminando a necessidade de limpeza em risco.

Ao fim da pesquisa, o projeto conceitual foi detalhado e entregue impresso à família, juntamente com a oferta de apoio gratuito no acompanhamento da realização das adequações. A proposta de reforma foi aceita pela família e o processo de reestruturação está em fase inicial. Ao término das alterações no espaço, uma nova avaliação no ambiente será realizada, sob o foco de verificação do índice de adequação ergonômica do projeto executado.

\section{CONCLUSÕES}

Para as limitações físicas identificadas no público alvo, verifica-se que existe um aumento na abrangência de problemas decorrentes do avanço da idade. Conclui-se então que, foi de extrema importância conhecer bem o público alvo, detectando suas limitações e assim, antecipar riscos. Os puxadores se revelaram um problema em mobiliários de cozinha, que além do risco de provocar lesões por contusão, também existe o risco de não estar adequado ao usuário em relação a realização da atividade, tanto o puxador, como a ausência dele. Portanto, é imprescindível que o ergonomista considere todas as limitações que o usuário possa vir a apresentar, e assim elaborar recomendações que promovam total 


\section{(x) $^{\text {enack }}$}

liberdade, autonomia e satisfação do usuário.

Através das contribuições da Ergonomia, notou-se que é possível a construção de um ambiente ergonômico, voltado para o usuário idoso acometido de Chykungunia e suas consequências musculoesqueléticas. As recomendações apresentadas trazem algumas vantagens para o usuário idoso acometido pela chikungunya, como a adaptação das cores do ambiente ao usuário e a iluminação adequada, visando a diminuição da acuidade visual. Novos puxadores embutidos foram adaptados para esse projeto, considerando a perda do manejo fino e a familiaridade do usuário com esse tipo de objeto. As recomendações também evidenciam vantagens para a antropometria, quanto às medidas do mobiliário para alturas, larguras e profundidades, visando futuras posturas assumidas e alcances desejados. Houve um ganho em espaço para circulação através do mobiliário homogêneo, além de facilitar a atividade de limpeza, tornando-a bastante rápida, outro fator determinante para a limpeza é o mobiliário inferior completamente suspenso.

Ao término da pesquisa, ficou claro que as recomendações ergonomizadoras propostas não precisam ser de uso exclusivo por parte de idosos acometidos pela Chikungunya, as sugestões se adequam a idosos saudáveis sem maiores problemas. O estudo evidenciou 0 fato de que as consequências da enfermidade só agravam os sintomas do processo natural de envelhecimento, fazendo com ergonomistas precisem tomar ainda mais cautela em relação a tais limitações. Viu-se que o estudo de projetos de ambientes para idosos se revela deveras importante, pois pode no futuro ajudar a garantir uma melhor qualidade de vida para esta parcela da população.

\section{REFERÊNCIAS BIBLIOGRÁFICAS}

AMERICAN COLLEGE OF RHEUMATOLOGY. Subcommittee on Rheumatoid Arthritis Guidelines: Guidelines for the management of rheumatoid arthritis. Arthitis Rheum, 2002; 46: 328-46.

ARAÚJO, Maria Creuza Borges; MORAIS, Suelyn Aciole; ARAUJO, Ivanildo Fernandes; SANTOS, Maria Betania Gama. Avaliação dos riscos físicos no ambiente residencial e sua influência na qualidade de vida na terceira idade. In: XXVIII Enegep - Encontro Nacional de Engenharia de Produção. Rio de Janeiro, RJ, Brasil, 13 a 16 de outubro de 2008.

ATTAIANESE Erminia; DUCA, Gabriella. Human factors and ergonomic principles in building design for life and work activities: an applied methodology. Special Issue: Ergonomics in Design - Part II. Theoretical Issues in Ergonomics Science. Volume 13, Issue 2, 2012. pg 187-202.

BEZERRA, Mariana; BARROS, Bruno. Idosos versus ambientes reduzidos: discussões e projeto para uma cozinha de dimensões mínimas. In: Um novo olhar para o projeto 2: a ergonomia no ambiente construído. Editora: UFPE, 2014.

BIASOLI, MC. Tratamento fisioterápico na terceira idade. Rev. Bras. Med. 2007 nov; 64:62-68. Edição especial.

FAPERJ / iUsEr, 2004. P. 167 - 174. BRASIL, Ministério da Saúde. Secretaria de Vigilância em Saúde. Departamento de Vigilância das Doenças Transmissíveis. Preparação e Resposta à Introdução do Vírus Chikungunya no Brasil. Brasília/ DF. 2014.

BRASIL, OPAS - Organização Pan-Americana da Saúde. Preparativos e resposta para o vírus de Chikungunya nas Américas. Informação para profissionais da área da saúde: Febre Chikungunya. Washington, D.C.Disp: <http:/www.paho.org/hq/index.phpoption=com_docman\&task=doc_download\&gid=16984\&ltemid=\&la $\mathrm{ng}=\mathrm{en}>\mathrm{em} 2011 \mathrm{e}$ acessado em julho de $201 \overline{4}$.

CLARES, Jorge Wilker Bezerra; FREITAS, Maria Célia; BORGES, Cíntia Lira. Fatores sociais e 


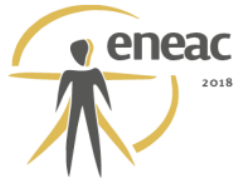

clínicos que causam limitação da mobilidade de idosos. Universidade Estadual do Ceará, Fortaleza, CE, Brasil. In: Acta Paulista de Enfermagem, 2014; 27(3): 237-42.

FABRÍCIO, Suzele Cristina Coelho; RODRIGUES, Rosalina A. Partezani; COSTA JUNIOR, Moacyr Lobo da. Causas e consequências de quedas em idosos atendidos em hospital público. Revista Saúde Pública. Ribeirão Preto, 2004; 38(1): 93-9. Disponível em: <http://www.scielo.br/pdf/rsp/v38n1/18457.pdf>. Acesso em: 20 jun. 2014.

FADIGATTI, Thaylla F. Mazzei; RIGOLINO, Marcelo Rolan; MEDOLA, Fausto Orsi; PASCHOARELLII, Luiz Carlos. Necessidades especiais e dificuldades do idoso no ambiente de supermercado: uma revisão dos aspectos ergonômicos. In 15 ERGODESIGN \& USIHC, Recife, 2015.

GUBERT, Marjorie. Design de Interiores: a padronagem como elemento compositivo no ambiente contemporâneo. Universidade Federal do Rio Grande do Sul, Dissertação de Mestrado, Porto Alegre - RS, 2011.

IBGE. Síntese de Indicadores Sociais: Uma Análise das Condições de Vida da População Brasileira: 2010, p. 191. Disponível em: <http://teen.ibge.gov.br/mao-na-roda/idosos> Acesso em: 30 maio de 2016.

IIDA, I. Ergonomia projeto e produção. 2ª . ed. São Paulo: Edgard Blucher, 2005.

LIPSKI PE. Rheumatoid arthritis. In: Kasper DL, Braunwald. E, Fauci AS, et al. Harrison's Principles of Internal Medicine. International edition, 14th ed., New York: McGraw Hill, 1998.

LUIZ, Lívia C.; REBELATTO, José R.; COIMBRA, Arlete M.V.; RICCI, Natalia A. Associação entre déficit visual e aspectos clínico-funcionais em idosos da comunidade. Revista Brasileira de Fisioterapia. Departamento de Fisioterapia, UFSCar. Recebido: 18/11/2008 - Revisado: 17/02/2009 - Aceito: 10/03/2009.

MOLINA, Flávia; BRAIDA, Frederico; ABDALLA, José Gustavo. A contribuição da ergonomia no estudo da prevenção de risco de queda de idosos em ambientes domiciliares. In: 15 ERGODESIGN \& USIHC, Recife - PE, 2015.

NEUFERT, Ernst. Arte de Projetar em Arquitetura. $18^{\circ}$ ed. São Paulo: Gustavo Gili do Brasil S.A., 2013.

ONU BR - Nações Unidos no Brasil. A ONU e as pessoas idosas. Disponível em: <http://www.onu.org.br/a-onu-em-acao/a-onu-em-acao/a-onu-e-as-pessoas-idosas/>. Acesso em: 30 maio 2016.

ORGANIZAÇÃO MUNDIAL DA SAÚDE. Envelhecimento ativo: uma política de saúde. Tradução Suzana Gontijo. 1aㅡ edição. Brasília: Organização Pan-Americana da Saúde, 2005.

PANERO, Julius; MARTIN, Zelnik. Dimensionamento humano para espaços interiores. Editora G. Gili, Ltda, 2013.

SÂMIA, Carolina. Cozinha funcional: análise do espaço e do usuário idoso. Faculdade de Arquitetura e Urbanismo da Universidade de São Paulo. Dissertação de Mestrado, São Paulo - SP, 2008. Acesso em 01 de julho de 2016.

SOCIEDADE BRASILEIRA DE REUMATOLOGIA. Comissão de Artrite Reumatoide da. Artrite Reumatoide: Cartilha para pacientes, 2011. www. reumatologia.org.br. Disponível em: <file:///C:/UFPE/PG\%201/Artigos/Chikungunya/cartilha\%20artrite\%20reumatoide.pdf > Acesso em 25 de junho de 2016.

TORTORA, GJ; FUNKE, B.; CASE C. Febre de Chikungunya. Microbiologia. Editora Artmed. 2012. Pag. 658. 